\title{
Effect of Temperature on Sporulation of Botryosphaeria dothidea, B. obtusa, and $B$. rhodina
}

\author{
W. E. Copes, Small Fruit Research Station, USDA-ARS, Poplarville, MS 39470; and F. F. Hendrix, Jr., Professor \\ Emeritus, Department of Plant Pathology, University of Georgia, Athens, GA
}

\begin{abstract}
Copes, W. E., and Hendrix, F. F., Jr. 2004. Effect of temperature on sporulation of Botryosphaeria dothidea, B. obtusa, and B. rhodina. Plant Dis. 88:292-296.

Three Botryosphaeria spp. were grown on autoclaved apple and peach stems in cotton-plugged tubes with constant moisture at $6,12,18,24$, and $30^{\circ} \mathrm{C}$ to determine the effect of temperature on sporulation. Number of conidia per pycnidium was determined weekly from 4 to 10 weeks after inoculation. The experiment was repeated three times. Maximum sporulation occurred at $24^{\circ} \mathrm{C}$ with $B$. dothidea and at 18 and $24^{\circ} \mathrm{C}$ with $B$. obtusa. Spore production of both fungi showed a quadratic curvilinear response to temperature. Pycnidia were erumpent, typical of their habit in nature. Maximum sporulation of $B$. rhodina occurred at 12,24 , and $30^{\circ} \mathrm{C}$ instead of at a distinctive peak. Of the three fungi, $B$. rhodina produced the greatest number of conidia per pycnidium at all temperatures. Mycelia and pycnidia of $B$. rhodina grew on top of the bark, which is atypical of their habit in nature. For spore production by $B$. dothidea, there was a significant interaction between temperature and time. Maximum sporulation over the 10 -week period occurred in week 4 and/or 6 for $B$. dothidea at 12,18 , and $24^{\circ} \mathrm{C}$, with a linear response at 12 and $24^{\circ} \mathrm{C}(P \leq$ 0.05 ). Conidial maturation of $B$. obtusa and $B$. rhodina had a quadratic curvilinear response due to temperature, with a maximum maturation at 12,18 , and $24^{\circ} \mathrm{C}$ with $B$. obtusa and at $24^{\circ} \mathrm{C}$ with $B$. rhodina. Spore maturation would affect longevity of conidial viability. Maximum spore production over time and percent pigmented spores over time by $B$. obtusa, and spore maturation over time by $B$. rhodina occurred in weeks 8,9 , and 10 with a significant linear response $(P \leq$ 0.05). All three Botryosphaeria spp. produced conidia over the 6 to $30^{\circ} \mathrm{C}$ range and over the 7week period (weeks 4 to 10), with maximum sporulation or spore maturation at 18 to $24^{\circ} \mathrm{C}$.
\end{abstract}

Additional keywords: black rot, bot canker, dieback

Botryosphaeria dothidea (Moug.:Fr.) Ces. \& De Not, B. obtusa (Schwein.) Shoemaker, and $B$. rhodina (Cooke) Arx are causative agents of dieback on many fruit, nut, and ornamental woody plants. Ascospores are considered to be a large percentage of the primary inoculum in cooler areas of the United States, such as the Upper Piedmont and mountains of North Carolina and further north, but a small percentage of the primary inoculum in most of the southeastern United States, including the mountains of Georgia $(3,5,9,19)$. In the southern areas, conidia serve as primary and secondary inoculum of all three pathogens (5).

Temperature ranges for conidial germination and mycelial growth are similar but not identical for $B$. dothidea, B. obtusa, and $B$. rhodina. Conidial germination for B. dothidea occurred from 12 to $39^{\circ} \mathrm{C}$,

Corresponding author: W. E. Copes

E-mail: wcopes@ars.usda.gov

Accepted for publication 23 October 2003.

Publication no. D-2004-0112-01R

This article is in the public domain and not copyrightable. It may be freely reprinted with customary crediting of the source. The American Phytopathological Society, 2004 with the peak from 24 to $36^{\circ} \mathrm{C}$, and no germination at $9^{\circ} \mathrm{C}$ in one study (14) and from 8 to $32^{\circ} \mathrm{C}$, with the peak from 20 to $28^{\circ} \mathrm{C}$, and no germination at $4^{\circ} \mathrm{C}$ in another study (20). Conidial germination for B. obtusa occurred from 12 to $32^{\circ} \mathrm{C}$, with the peak from 16 to $28^{\circ} \mathrm{C}$, and no germination at $8^{\circ} \mathrm{C}$ in one study (1), from 8 to $36^{\circ} \mathrm{C}$, with the peak from 16 to $32^{\circ} \mathrm{C}$, and no germination at $4^{\circ} \mathrm{C}$ in a second study (7), and from 12 to $32^{\circ} \mathrm{C}$, with the peak from 27 to $32^{\circ} \mathrm{C}$, and no germination at $8^{\circ} \mathrm{C}$ in a third study $(8)$. The temperature range for germination has not been determined for $B$. rhodina. Mycelial growth for $B$. dothidea has been reported to occur from 10 to $35^{\circ} \mathrm{C}$, with a peak from 20 to $32^{\circ} \mathrm{C}$, and no growth at 0,5 , and $40^{\circ} \mathrm{C}$ $(14,18,24)$. Mycelial growth for $B$. obtusa occurred from 8 to $36^{\circ} \mathrm{C}$, with a peak from 20 to $26^{\circ} \mathrm{C}$, and no growth at $4^{\circ} \mathrm{C}(7,8)$. Voorhees (22) found that mycelial growth for $B$. rhodina occurred from 15 to $35^{\circ} \mathrm{C}$, with a peak from 25 to $35^{\circ} \mathrm{C}$, and little to no growth at 10 and $40^{\circ} \mathrm{C}$.

The differences in seasonal ranges for conidial production among these Botryosphaeria spp. are greater than the differences in the in vitro germination and mycelial growth. Weaver $(23,24)$ recovered $B$. dothidea conidia from 22 March to 30 December, with peak number of conidia collected in late July and early August Creswell and Milholland (6) recovered high numbers of conidia of $B$. dothidea from blighted blueberry stems from June through August and low numbers from February through May and in September. Some researchers have found viable pycnidia of $B$. dothidea produced throughout the year on dead stems of elm (11), pistachio (12,13), and peach (15). A similar but slightly earlier summer trend has been documented for B. obtusa, with high numbers of conidia recovered from midMarch through August from apple twigs killed by fire blight in North Carolina (2). Yet in Georgia, conidial production during winter and spring months was attributed to B. obtusa $(3,4,21)$. Pycnidia of B. obtusa found on dead apple stems contained mature conidia in January and February, with $90 \%$ of the pycnidia empty by the end of April (21). B. obtusa conidia were isolated from apple buds from October through the silver tip stage in March and from peach buds from August to March, with peak recovery in January and February $(3,4)$. Conidia of $B$. rhodina were recovered from peach trees starting in mid-March, with peak recovery occurring sporadically from early June to late July, and limited or no recovery during winter months $(4,16)$. $B$. rhodina is the least common of the three species isolated from diseased peach stems.

Small geographic differences in pathogen and fruit tree phenology can be important in developing and timing control measures. Sporulation has been predominately studied in vivo, often in the field using spore trapping techniques (15). The objective of this study was to measure in vitro sporulation for $B$. dothidea, $B$. obtusa, and B. rhodina from 6 to $32^{\circ} \mathrm{C}$ at 6degree increments and determine if sporulation was affected by nutrient differences between apple and peach stems as the substrate.

\section{MATERIALS AND METHODS}

Experiment design. The experiment was conducted in incubators to test the effect of temperature $(6,12,18,24$, and $30^{\circ} \mathrm{C}$ ) on conidial production. The experiment was conducted three times. A Latin square design pattern with two squares allowed testing for the effect from individual incubators across the three repetitions of the experiment, hereon referred to as periods. One Latin square consisted of 6 , 
12 , and $18^{\circ} \mathrm{C}$, and the second Latin square consisted of 12,24 , and $30^{\circ} \mathrm{C}$. Within a Latin square, each temperature was tested in each of the three incubators over the three periods. One temperature $\left(12^{\circ} \mathrm{C}\right)$ was repeated in both Latin squares to test significance between Latin squares, with the possibility of combining squares into one data set. Within one period, all incubator tests of both Latin squares were run concurrently. A period lasted 10 weeks from the time inoculated stems were placed in incubators until the final sampling.

Inoculation and stem culture maintenance. Straight, 4- to 7-mm-diameter water sprouts were obtained from apple and peach trees. The stems were cut into segments $1 \mathrm{~cm}$ long, and a single stem segment was placed in a $12 \times 75 \mathrm{~mm} \mathrm{Kimax}$ disposable borosilicate glass tube. The tubes were plugged with nonabsorbent cotton and autoclaved at $121^{\circ} \mathrm{C}$ for $1 \mathrm{~h}$.

Isolates of $B$. dothidea, B. obtusa, and $B$. rhodina were obtained from apple and peach orchards prior to each period and grown on potato dextrose agar for 14 to 21 days. Cultures were covered with $0.01 \%$ Tween 20 , and pycnidia were scraped free with a rubber policeman for $B$. dothidea and $B$. rhodina and an aluminum spatula for B. obtusa. Pycnidia were crushed with a ceramic mortar and pestle and filtered through four layers of sterile cheesecloth. Conidial concentrations were determined with a hemacytometer and adjusted to $4 \times$ $10^{4}$ conidia per ml. Under a laminar air flow hood, $0.2 \mathrm{ml}$ of conidial suspension was applied to each stem segment with a hypodermic needle.

A tray contained three tubes (replications) of every fungus-host combination for a total of 18 tubes, which were completely randomized in two rows in the tray. Trays were constructed of cardboard and covered with aluminum foil with the shiny side up. Glass tubes containing stem segments were set at opposing angles of $25^{\circ}$ with the bases of tubes touching in the middle of the tray. Stem cultures were 10 to $12.5 \mathrm{~cm}$ below two fluorescent and two 25-watt incandescent bulbs, which provided approximately 75 to $45 \mu \mathrm{E} \cdot \mathrm{m}^{-2} \cdot \mathrm{s}^{-1}$ of intensity from the middle to the corner of the incubator, respectively. Seven trays of stem cultures, representing 7 weeks of sampling, were completely randomized in two rows in the incubator at zero time. All incubators were initially set at $25^{\circ} \mathrm{C}$ for 5 days to allow for spore germination and initial colonization of the stem, then incubators were adjusted to the appropriate temperature, which took approximately $4 \mathrm{~h}$.

Sterile deionized water was added to tubes as needed in a laminar air flow hood. Water was added up to twice a week to tubes in the $30^{\circ} \mathrm{C}$ incubator and as little as every 2 weeks to tubes in the $6^{\circ} \mathrm{C}$ incubator.

Sampling. Sampling began the fourth week after inoculation and continued for 7 weeks. One tray was removed from each incubator every week. Two pycnidia were cut from the center region of each stem and placed in separate $7.4-\mathrm{ml}$ glass vials. Sterilized water $(0.1 \mathrm{ml})$ was added to each vial. Each pycnidium was crushed with the flat end of a metal rod, and the contents of the vial were stirred. Two $10-\mu l$ volumes were removed and injected into two counting wells. Counting wells were custom made with two hemacytometer coverslips, each with a 6-mm-diameter hole sandblasted in the center, that had been glued with epoxy to a glass slide. All conidia within both wells were counted, added, and multiplied by five to calculate conidia per pycnidium.

Statistical analysis. Analysis of variance was preformed to test the fixed effect of temperature $\left(6,12,18,24\right.$, and $\left.30^{\circ} \mathrm{C}\right)$, time (weeks 4 to 10 ), interaction between temperature and time, host (apple and peach stems), and Latin square (1 and 2) on the average number of conidia per pycnidium (CN/P) for each Botryosphaeria spp. (B. dothidea, B. obtusa, and B. rhodina) and average percent conidia that developed dark pigmentation and/or septum for species with those characters using the MIXED procedure of SAS (Version 8.2, SAS Institute, Cary, NC). Error terms included the random effects of period (treated as experimental blocks) and replication, and the interaction of the fixed factors (10). Differences among factors and levels were determined by pairwise comparison of $t$ tests for the statistical significance of the difference between least square means (LSMEANS). Orthogonal contrasts of LSMEANS were used to test linear and curvilinear relationships of model parameters.

Table 1. Significance of temperature $\left(6,12,18,24\right.$, and $30^{\circ} \mathrm{C}$ ), time (from week 4 to 10 after inoculation), and interaction between temperature and time on the number of conidia per pycnidium for Botryosphaeria dothidea

\begin{tabular}{lccr}
\hline Factor, trend & df & $\boldsymbol{F}$ value & $\boldsymbol{P}>\boldsymbol{F}^{\mathbf{a}}$ \\
\hline Temperature & 4 & 17.40 & $<0.0001$ \\
Linear & 1 & 3.70 & 0.0548 \\
Quadratic & 1 & 8.76 & 0.0032 \\
Time & 6 & 4.81 & $<0.0001$ \\
Linear & 1 & 8.57 & 0.0035 \\
Quadratic & 1 & 0.79 & 0.3731 \\
Temperature $\times$ time & 24 & 2.30 & 0.0005
\end{tabular}

${ }^{a}$ Data were analyzed using PROC MIXED (SAS Institute, Cary, NC) and linear and quadratic responses determined by contrast of least square means.

\section{RESULTS}

At all temperatures, pycnidium development began at the ends of the stem segments during the second week and formed in the middle of stem segments during the third week. All three Botryosphaeria spp. produced conidia at the five temperatures tested. The mycelium of $B$. dothidea and $B$. obtusa grew below the bark, and the pycnidia erumped through the bark. The mycelium and pycnidia of $B$. rhodina grew above the bark, atypical of its habit in nature.

Latin square based on comparison of the data at the $12^{\circ} \mathrm{C}$ temperature was not significantly different $(P=0.0765,0.1012$, and 0.4185 for $B$. dothidea, B. obtusa, and $B$. rhodina, respectively). Therefore, temperatures from the two Latin squares were treated as one data set, and data from the two $12^{\circ} \mathrm{C}$ treatments were combined. Host was not significantly different $(P \leq 0.05)$ for $B$. dothidea, B. obtusa, and B. rhodina. Therefore, replications from weekly conidial counts from both hosts were combined.

For $B$. dothidea, $\mathrm{CN} / \mathrm{P}$ was significant $(P \leq 0.05)$ as affected by temperature, time, and the interaction of temperature and time (Table 1). Sporulation peaked at $24^{\circ} \mathrm{C}$ (Fig. 1). Sporulation decreased over time, with the largest reductions in $\mathrm{CN} / \mathrm{P}$ at 18 and $24^{\circ} \mathrm{C}$ (Fig. 2).

For B. obtusa, conidial counts were only available for two periods because contamination with other fungi, particularly an unidentified fungus hyperparasitic on $B$. obtusa and an Alternaria sp., detrimentally affected spore production in one period. Temperature significantly affected sporulation and the percent conidia with dark pigmentation of $B$. obtusa $(P \leq 0.05)$ with a quadratic curvilinear response (Table 2 ). $\mathrm{CN} / \mathrm{P}$ was highest at 18 and $24^{\circ} \mathrm{C}$, with the least number produced at 6 and $30^{\circ} \mathrm{C}$ (Fig $1)$. The percent conidia with dark pigmentation was highest at 12,18 , and $24^{\circ} \mathrm{C}$ (Fig. 3). CN/P and the percent conidia with

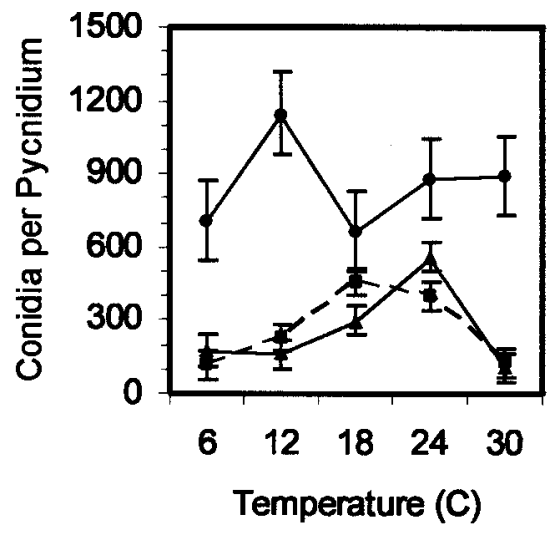

Fig. 1. Mean conidial number per pycnidium averaged over a 7 -week sampling period produced at $6,12,18,24$, and $30^{\circ} \mathrm{C}$ for Botryosphaeria dothidea ( $\boldsymbol{\Lambda}$ and solid line), B. obtusa ( and long-dashed line), and B. rhodina ( and solid line). Bars are standard deviation of least square means based on PROC MIXED analysis $(P \leq 0.05)$. 
dark pigmentation of $B$. obtusa significantly increased over time $(P \leq 0.05)$ with a significant linear response (Table 2). Maximum sporulation occurred in weeks 8 and 10 (Fig. 4). The percent conidia with dark pigmentation was highest at weeks 7 , 8, 9, and 10 (Fig. 5).

For $B$. rhodina, $\mathrm{CN} / \mathrm{P}$ was significantly $(P \leq 0.05)$ different due to temperature, but not significant for linear or quadratic response patterns (Table 3). $\mathrm{CN} / \mathrm{P}$ were highest at 12,24 , and $30^{\circ} \mathrm{C}$, but means at 24 and $30^{\circ} \mathrm{C}$ were not different from means at 6 and $18^{\circ} \mathrm{C}$ (Fig. 1). The mean $\mathrm{CN} / \mathrm{P}$ were higher at all five temperatures for $B$. rhodina than at the temperature with the highest mean for $B$. dothidea and $B$. obtusa (Fig. 1). For B. rhodina, CN/P were not significantly different $(P \leq 0.05)$ over time (Table 3, Fig. 4).

Despite the small differences between $\mathrm{CN} / \mathrm{P}$ due to temperature for $B$. rhodina, the percent conidia with dark pigmentation and percent pigmented conidia with a sep- tum were significantly different $(P \leq 0.05)$ due to temperature and time for $B$. rhodina (Table 3). Percent conidia with dark pigmentation was lowest at $6^{\circ} \mathrm{C}$ and highest at $24^{\circ} \mathrm{C}$, with significant linear and quadratic curvilinear responses $(P \leq 0.05)$ (Table 3 , Fig. 6). Percent pigmented conidia with a septum were lowest at 6 and $30^{\circ} \mathrm{C}$ and highest at 12 and $24^{\circ} \mathrm{C}$, with a significant quadratic curvilinear response. Percent conidia with pigmentation and percent pigmented conidia with a septum increased over time $(P \leq 0.05)$, with a significant linear response (Table 3). Maximum percent conidia with dark pigmentation and percent pigmented conidia with a septum occurred in weeks 8,9 , and 10 ; and weeks 9 and 10, respectively (Fig. 7).

\section{DISCUSSION}

Conidia of B. dothidea, B. obtusa, and $B$. rhodina were produced at all temperatures tested. Conidial production occurred at $6^{\circ} \mathrm{C}$, which is below or near tempera-

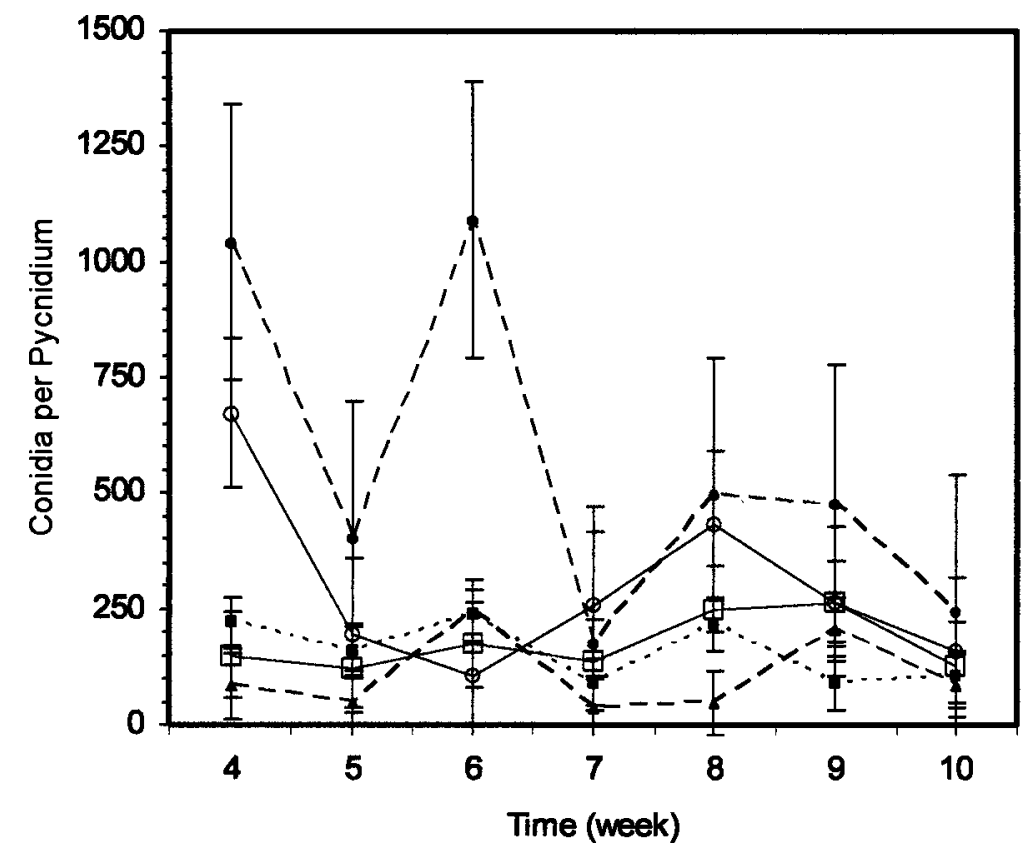

Fig. 2. Mean conidial number per pycnidium per week from 4 to 10 weeks after inoculation for Botryosphaeria dothidea at 6 ( $\square$ and solid line), 12 ( $\square$ and short-dashed line), 18 ( $O$ and solid line), 24 ( $\bullet$ and long-dashed line), and $30^{\circ} \mathrm{C}$ ( $\boldsymbol{\Delta}$ and long-dashed line). Bars are standard deviation of least square means based on PROC MIXED analysis $(P \leq 0.05)$.

Table 2. Significance of temperature $\left(6,12,18,24\right.$, and $30^{\circ} \mathrm{C}$ ), time (from week 4 to 10 after inoculation), and interaction between temperature and time on the number of conidia per pycnidium and percent conidia with dark pigmentation for Botryosphaeria obtusa

\begin{tabular}{lcccccccr}
\hline & \multicolumn{3}{c}{$\begin{array}{c}\text { Number of conidia } \\
\text { per pycnidium }\end{array}$} & & \multicolumn{3}{c}{$\begin{array}{c}\text { Percent conidia } \\
\text { with dark pigmentation }\end{array}$} \\
\cline { 2 - 4 } \cline { 6 - 8 } Factor, trend & $\mathbf{d f}$ & $\boldsymbol{F}$ value & $\boldsymbol{P}>\boldsymbol{F}^{\mathbf{a}}$ & & df & $\boldsymbol{F}$ value & \multicolumn{1}{c}{$\boldsymbol{P} \boldsymbol{F}$} \\
\hline Temperature & 4 & 13.97 & $<0.0001$ & & 4 & 12.49 & $<0.0001$ \\
Linear & 1 & 1.14 & 0.2861 & & 1 & 1.88 & 0.1709 \\
Quadratic & 1 & 43.64 & $<0.0001$ & & 1 & 26.12 & $<0.0001$ \\
Time & 6 & 8.03 & 0.0002 & & 6 & 4.45 & 0.0002 \\
Linear & 1 & 21.03 & $<0.0001$ & & 1 & 17.51 & $<0.0001$ \\
Quadratic & 1 & 3.80 & 0.0521 & & 1 & 0.12 & 0.7243 \\
Temperature $\times$ time & 24 & 1.04 & 0.4103 & & 24 & 1.02 & 0.4362 \\
\hline
\end{tabular}

${ }^{a}$ Data were analyzed using PROC MIXED (SAS Institute, Cary, NC) and linear and quadratic responses determined by contrast of least square means. tures at which conidial germination or mycelial growth does not occur. A hypothesis, not tested in this study, is that conidial production could be initiated at

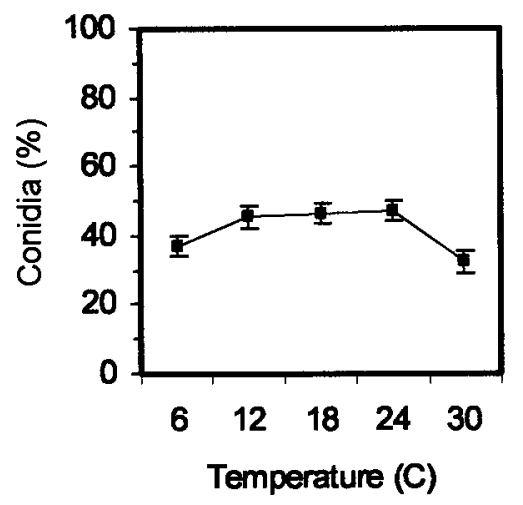

Fig. 3. Percent conidia of Botryosphaeria $o b$ tusa with dark pigmentation ( $\mathbf{\square})$ averaged over a 7 -week sampling period at $6,12,18,24$, and $30^{\circ} \mathrm{C}$. Bars are standard deviation of least square means based on PROC MIXED analysis $(P \leq 0.05)$

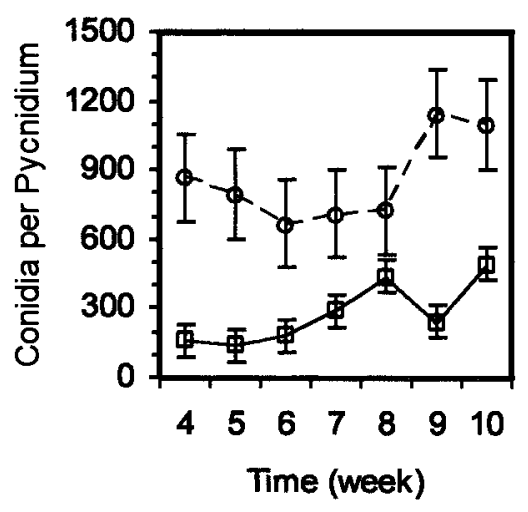

Fig. 4. Mean conidial number per pycnidium per week averaged over five temperatures $(6,12,18$, 24 , and $30^{\circ} \mathrm{C}$ ) from 4 to 10 weeks after inoculation for Botryosphaeria obtusa ( $\square$ and solid line) and $B$. rhodina ( $\mathrm{O}$ and dashed line). Bars are standard deviation of least square means based on PROC MIXED analysis $(P \leq 0.05)$.

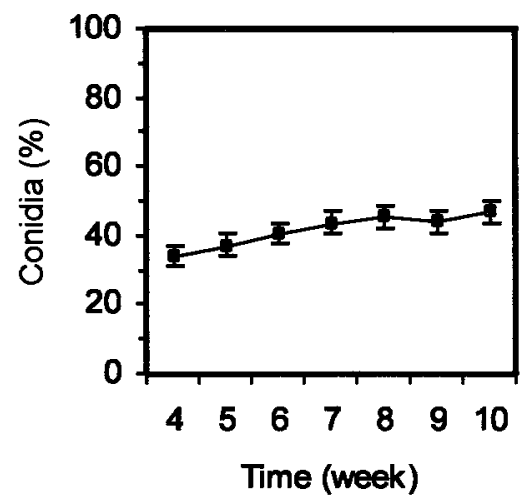

Fig. 5. Percent conidia of Botryosphaeria obtusa with dark pigmentation (ם) averaged over five temperatures $\left(6,12,18,24\right.$, and $\left.30^{\circ} \mathrm{C}\right)$ from 4 to 10 weeks after inoculation. Bars are standard deviation of least square means based on PROC MIXED analysis $(P \leq 0.05)$. 
low temperatures during winter so that mature conidia are available for release when temperatures are suitable for conidial germination. Particularly in the southeastern United States, temperatures fluctuate between cold and warm periods throughout the winter and spring seasons.

For $B$. dothidea, the in vitro temperature range found in this study corresponded with the temperatures that would occur during the months that Weaver (24) collected conidia in central Georgia. Weaver found no correlation between air temperature and the number of conidia collected. However, his collection methods depended on release of conidia, and release usually is in response to wetting $(9,13,17)$. While we found that conidia were produced over the 6 to $30^{\circ} \mathrm{C}$ range, peak sporulation occurred at $24^{\circ} \mathrm{C}$, with a moderate number of conidia produced at $18^{\circ} \mathrm{C}$. This suggests that $B$. dothidea may have a relatively narrow temperature range for peak conidia production.

Our data show that $B$. obtusa is capable of producing conidia at low temperatures, but to no greater degree than $B$. dothidea. Yet on apple and peach trees, B. obtusa has been recovered during the late fall, winter, and early spring months and is still active into early summer. Results in this study neither contradict nor provide additional insight to further explain Britton and Hendrix's (4) and Beisel et al.'s (3) bud infestation data, Taylor's (21) pycnidial collection data, and Sutton's (19) spore trap data. For B. obtusa, peak sporulation occurred at both 18 and $24^{\circ} \mathrm{C}$, with moderate sporulation at $12^{\circ} \mathrm{C}$, which suggests that $B$. obtusa has a broader temperature range for peak conidia production than does $B$. dothidea.

B. rhodina produced more conidia in vitro than the other species. However, it also exhibited a habit that would not be found in nature. The mycelium of $B$. rhodina grew profusely above the bark, and pycnidia formed above the bark also. The unnatural constant moisture maintained in this experiment probably contributed to this unusual growth habit. Voorhees (22) reported a similar growth habit for some $B$. rhodina isolates. $B$. rhodina is the least common of the three Botryosphaeria spp. in peach orchards (4). Brown and Britton
(5) suggested that its minor role was due to the production of copious amounts of gum by peach trees in response to infection by B. rhodina. However, Pusey (16) recovered $B$. rhodina from the outer bark and infrequently from inner bark layers, even when gumming was not evident. The atypical habit seen in Voorhees's (22) study and in all three experiments in our in vitro research suggests that $B$. rhodina may have a lower propensity to penetrate and colonize inner bark layers than the other two species. Environmental and/or host factors that regulate or influence $B$. rhodina's growth habits still need to be defined.

Despite the high numbers of $\mathrm{CN} / \mathrm{P}$ produced by $B$. rhodina over the 6 to $30^{\circ} \mathrm{C}$ range, conidial maturation was affected by temperature. Immature conidia of $B$. rhodina are hyaline. The typical maturation proceeds to development of a dark brown pigmentation in the cell wall, followed by production of a single central, horizontal septum. A low percentage of conidia were pigmented at $6^{\circ} \mathrm{C}$, with a high percentage having pigmentation at 12 to $30^{\circ} \mathrm{C}$ (Fig. 5). Of the pigmented conidia, $<50 \%$ had a septum at 6 and $30^{\circ} \mathrm{C}$, whereas $>60 \%$ formed septa at 12 to $24^{\circ} \mathrm{C}$. Based on these results and the general knowledge that hyaline conidia are more susceptible to damage from UV radiation, a higher number of conidia could remain

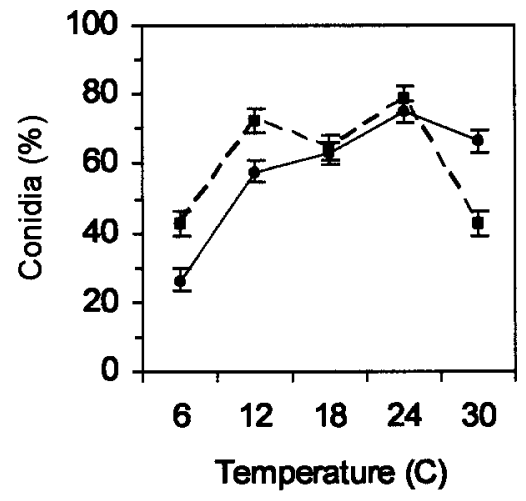

Fig. 6. Percent conidia of Botryosphaeria rhodina with dark pigmentation ( $\bullet$ and solid line) and pigmented conidia with a septum ( $\square$ and dashed line) averaged over a 7-week sampling period at $6,12,18,24$, and $30^{\circ} \mathrm{C}$. Bars are standard deviation of least square means based on PROC MIXED analysis $(P \leq 0.05)$. viable for longer at 12 to $24^{\circ} \mathrm{C}$. These results need to be documented under natural conditions to understand the extent that temperature impacts prevalence of $B$. rhodina.

The pattern of change in CN/P over time differed with each Botryosphaeria spp. $\mathrm{CN} / \mathrm{P}$ decreased over a 7-week period with $B$. dothidea, increased over time with $B$. obtusa, and did not change significantly over time with $B$. rhodina. For B. rhodina, the percentage of mature conidia (darkly pigmented with a septum) increased over time in a similar linear pattern to $\mathrm{CN} / \mathrm{P}$ for $B$. obtusa. In our study, natural moisture events that would result in the release and dispersal of conidia did not occur; therefore, conidia potentially remained associated longer with pycnidia than would occur in nature. When water was added to a tube, it was directed to flow down the side of the tube; therefore, conidia would more likely be dispersed at the lower half than at the middle to upper half of the stem.

The study did not demonstrate how $\mathrm{CN} / \mathrm{P}$ correlated with field measures of the number of conidia per stem area, which would have required additional measurements such as the number of pycnidia per stem area. Nor did we measure the length of time that Botryosphaeria spp. could

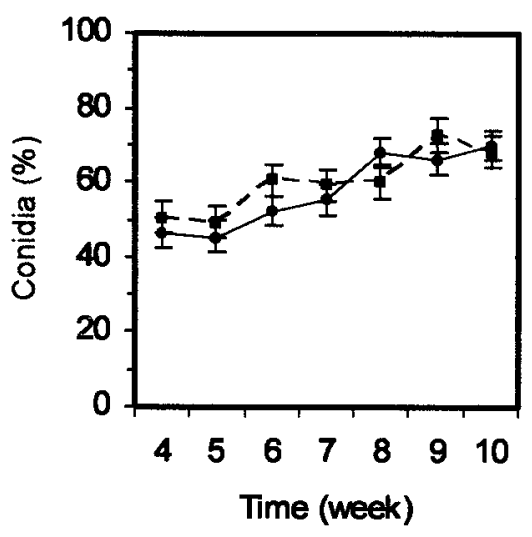

Fig. 7. Percent conidia of Botryosphaeria rhodina with dark pigmentation ( and solid line) and pigmented conidia with a septum ( and dashed line) averaged over five temperatures $\left(6,12,18,24\right.$, and $\left.30^{\circ} \mathrm{C}\right)$ from 4 to 10 weeks after inoculation. Bars are standard deviation of least square means based on PROC MIXED analysis $(P \leq 0.05)$.

Table 3. Significance of temperature $\left(6,12,18,24\right.$, and $30^{\circ} \mathrm{C}$ ), time (from week 4 to 10 after inoculation), and interaction between temperature and time on the number of conidia per pycnidium, percent conidia with dark pigmentation, and percent pigmented conidia with a septum for Botryosphaeria rhodina

\begin{tabular}{|c|c|c|c|c|c|c|c|c|c|}
\hline \multirow[b]{2}{*}{ Factor, trend } & \multicolumn{3}{|c|}{$\begin{array}{l}\text { Number of conidia } \\
\text { per pycnidium }\end{array}$} & \multicolumn{3}{|c|}{$\begin{array}{c}\text { Percent conidia } \\
\text { with dark pigmentation }\end{array}$} & \multicolumn{3}{|c|}{$\begin{array}{c}\text { Percent pigmented conidia } \\
\text { with a septum }\end{array}$} \\
\hline & df & $F$ value & $P>F^{a}$ & df & $F$ value & $P>F$ & df & $F$ value & $P>F$ \\
\hline Temperature & 4 & 2.74 & 0.0281 & 4 & 61.49 & $<0.0001$ & 4 & 41.21 & $<0.0001$ \\
\hline Linear & 1 & 0.07 & 0.7981 & 1 & 168.56 & $<0.0001$ & 1 & 0.51 & 0.4759 \\
\hline Quadratic & 1 & 0.97 & 0.3247 & 1 & 32.05 & $<0.0001$ & 1 & 48.16 & $<0.0001$ \\
\hline Time & 6 & 1.96 & 0.0695 & 6 & 13.48 & $<0.0001$ & 6 & 7.46 & $<0.0001$ \\
\hline Linear & 1 & 0.70 & 0.4019 & 1 & 35.51 & $<0.0001$ & 1 & 8.60 & 0.0035 \\
\hline Quadratic & 1 & 0.58 & 0.4457 & 1 & 1.83 & 0.1766 & 1 & 1.90 & 0.1685 \\
\hline Temperature $\times$ time & 24 & 0.99 & 0.4745 & 24 & 1.03 & 0.4269 & 24 & 1.90 & 0.25859 \\
\hline
\end{tabular}

a Data were analyzed using PROC MIXED (SAS Institute, Cary, NC) and linear and quadratic responses determined by contrast of least square means. 
continue to colonize and produce conidia from a section of stem, which would require longer stem sections to simulate progressive stem colonization.

The data from our study do not directly contribute to improving control strategies of the diseases caused by Botryosphaeria spp., but they do provide basic information to be used in combination with spore trapping data, temperature ranges of conidium germination, and seasonal recovery of pathogens from plant tissue to better understand the seasonal behavior of these pathogens. Our study demonstrates that in vitro temperature ranges for sporulation and spore maturation can differ from those for spore germination and mycelial growth.

\section{LITERATURE CITED}

1. Arauz, L. F., and Sutton, T. B. 1989. Influence of temperature and moisture on germination of ascospores and conidia of Botryosphaeria obtusa. Phytopathology 79:667-674.

2. Aycock, R. 1949. Studies on Physalospora obtusa with emphasis upon the morphology and cytology of the perithecial stage. Ph.D. thesis. University of North Carolina, Raleigh.

3. Beisel, M., Hendrix, F. F., Jr., and Starkey, T. E. 1984. Natural inoculation of apple buds by Botryosphaeria obtusa. Phytopathology 74:335-338.

4. Britton, K. O., and Hendrix, F. F. 1989. Infection of peach buds by Botryosphaeria obtusa.
Plant Dis. 73:65-68.

5. Brown, E. A., II, and Britton, K. O. 1986. Botryosphaeria diseases of apple and peach in the southeastern United States. Plant Dis. 70:480-484.

6. Creswell, T. C., and Milholland, R. D. 1988. Spore release and infection periods of Botryosphaeria dothidea on blueberry in North Carolina. Plant Dis. 72:342-346.

7. Foster, H. H. 1937. Studies of the pathogenicity of Physalospora obtusa. Phytopathology 27:803-823.

8. Fulkerson, J. F. 1955. The relation of light to production of pycnidia by Physalospora obtusa. Phytopathology 45:22-25.

9. Holmes, J., and Rich, A. E. 1970. Factors affecting release and dissemination of Physalospora obtusa spores in a New Hampshire apple orchard. Phytopathology 60:1052-1054.

10. Littel, R. C., Milliken, G. A., Stroup, W. W., and Wolfinger, R. D. 1996. SAS system for mixed models. SAS Institute Inc., Cary, NC.

11. Luttrell, E. S. 1950. Botryosphaeria canker of elm. Plant Dis. Rep. 34:138-139.

12. Michailides, T. J. 1991. Pathogenicity, distribution, sources of inoculum, and infection courts of Botryosphaeria dothidea on pistachio. Phytopathology 81:566-573.

13. Michailides, T. J., and Morgan, D. P. 1993. Spore release by Botryosphaeria dothidea in pistachio orchards and disease control by altering the trajectory angle of sprinklers. Phytopathology 83:145-152.

14. Michailides, T. J., and Morgan, D. P. 1992. Effects of temperature and wetness duration on infection of pistachio by Botryosphaeria dothide $a$ and management of disease by reducing duration of irrigation. Phytopathology 82:1399-1406.

15. Pusey, P. L. 1989. Availability and dispersal of ascospores and conidia of Botryosphaeria in peach orchards. Phytopathology 79:635-639.

16. Pusey, P. L. 1993. Role of Botryosphaeria species in peach tree gummosis on the basis of differential isolation from outer and inner bark. Plant Dis. 77:170-174.

17. Pusey, P. L., and Bertrand, P. F. 1993. Seasonal infection of nonwounded peach bark by Botryosphaeria dothidea. Phytopathology 83:825829.

18. Spiers, A. G. 1977. Botryosphaeria dothidea infection of Salix species in New Zealand. Plant Dis. Rep. 61:664-667.

19. Sutton, T. B. 1981. Production and dispersal of ascospores and conidia by Physalospora $o b$ tusa and Botryosphaeria dothidea in apple orchards. Phytopathology 71:584-589.

20. Sutton, T. B., and Arauz, L. F. 1991. Influence of temperature and moisture on germination of ascospores and conidia of Botryosphaeria dothidea. Plant Dis. 75:1146-1149.

21. Taylor, J. 1959. The distinctive nature of some apple disease conditions in Georgia. Plant Dis. Rep. 43:654-657.

22. Voorhees, R. K. 1942. Life history and taxonomy of the fungus Physalospora rhodina. Univ. Fla. Agric. Tech. Bull. No. 371.

23. Weaver, D. J. 1974. A gummosis disease of peach trees caused by Botryosphaeria dothidea. Phytopathology 64:1429-1432.

24. Weaver, D. J. 1979. Role of conidia of Botryosphaeria dothidea in the natural spread of peach tree gummosis. Phytopathology 69:330334. 